\title{
Investigasi Pengaruh Air Laut Sebagai Air Pencampuran Dan Perawatan Terhadap Sifat Beton
}

\author{
Syamsul Bahri Ahmad ${ }^{1, a}$ \\ ${ }^{1}$ Jurusan Teknik Sipil Politeknik Negeri Ujung Pandang, Jl.Perintis Kemerdekaan KM 10 Makassar 90245 \\ a syamba_68@poliupg.ac.id
}

\begin{abstract}
Abstract Water is one of the most important ingredients in aggregate, cement and other additives if necessary so that the chemical process of cement that forms the paste as an aggregate binder. This study aims to investigate the effect of sea water as mixing-curing water of concrete toward the compressive strength, porosity and sorptivity of concrete. A number of test specimens with the size of $15 \mathrm{~cm} \times 30 \mathrm{~cm}$ and $10 \mathrm{~cm} \times 20 \mathrm{~cm}$ with content $450 \mathrm{~kg} / \mathrm{m} 3$ of cement tested at age 28 days with reference to ASTM standard. The results of study shows that compressive strength of concrete mixed with seawater (BLT and BLL) higher than concrete compressive strength mixed with fresh water (BTT and BTL) followed by decreasing of porosity of concrete. The compressive strength of concrete mixed and treated with seawater (BLL) obtained $352.29 \mathrm{~kg} / \mathrm{cm} 2$ with a porosity of $17.06 \%$ concrete. Compressive strength of concrete mixed with seawater and treated with fresh water (BLT) was obtained $331,61 \mathrm{~kg} / \mathrm{cm} 2$ with concrete porosity $16,87 \%$. Compressive strength of concrete mixed with fresh water and treated with fresh water (BTT) as comparative concrete obtained $314,05 \mathrm{~kg} / \mathrm{cm} 2$ with porosity $17,97 \%$. Compressive strength of concrete mixed with fresh water and treated with sea water (BTL) obtained $297,80 \mathrm{~kg} / \mathrm{cm} 2$ with porosity $16,44 \%$. Good concrete sorptivities showed by concrete treated with seawater (BTL and BLL).
\end{abstract}

Keywords : Sea-water, concrete, compressive strength, porosity and sorptivity

Abstrak-Air merupakan salah bahan yang sangat penting dalam campuran agregat, semen dan bahan tambah lain jika dibutuhkan agar terjadi proses kimiawi semen yang membentuk pasta sebagai pengikat agregat. Penelitian ini bertujuan untuk mengetahui pengaruh air laut sebagai air campuran dan perawatan beton terhadap kuat tekan, porositas dan sorptiviti beton. Sejumlah benda uji dengan ukuran $15 \mathrm{~cm}$ x $30 \mathrm{~cm}$ dan 10 $\mathrm{cm} \times 20 \mathrm{~cm}$ dengan kandungan semen $450 \mathrm{~kg} / \mathrm{m}^{3}$ diuji pada umur 28 hari dengan mengacu pada standar ASTM. Hasil penelitian menunjukkan bahwa kuat tekan beton yang dicampur dengan air laut (BLT dan BLL) mengalami peningkatan kuat tekan terhadap kuat tekan beton yang dicampur dengan air tawar (BTT dan BTL) yang diikuti dengan penurunan porositas beton. Kuat tekan beton yang dicampur dan dirawat dengan air laut (BLL) diperoleh $352,29 \mathrm{~kg} / \mathrm{cm}^{2}$ dengan porositas sebesar beton $17,06 \%$. Kuat tekan beton yang dicampur air laut dan dirawat dengan air tawar (BLT) diperoleh $331,61 \mathrm{~kg} / \mathrm{cm}^{2}$ dengan porositas beton $16,87 \%$. Kuat tekan beton yang dicampur dengan air tawar dan dirawat dengan air tawar (BTT) sebagai beton pembanding diperoleh $314,05 \mathrm{~kg} / \mathrm{cm}^{2}$ dengan porositas $17,97 \%$. Kuat tekan beton yang dicampur dengan air tawar dan dirawat dengan air laut (BTL) diperoleh $297,80 \mathrm{~kg} / \mathrm{cm}^{2}$ dengan porositas 16,44 \%. Sorptiviti beton yang baik cenderung ditunjukkan beton yang dirawat dengan air laut (BTL dan BLL).

Kata kunci : Air laut, beton, kuat tekan, porositas dan sorptiviti

\section{Pendahuluan}

Beton saat ini telah menjadi salah satu material utama pada bangunan yang sangat penting untuk memenuhi kebutuhan industri properti dan bangunan sipil. Dalam pelbagai bangunan infrastruktur yang ada di dunia ini, beton yang dibuat dengan menggunakan semen portland menjadi material terbesar yang paling banyak digunakan dibandingkan material lain seperti baja, kayu ataupun bambu. Industri beton merupakan pengguna sumber daya alam terbesar di dunia [1] [9]. Beton yang telah mengeras merupakan material gabungan yang terdiri dari agregat kasar, agregat halus, semen dan admixture atau bahan tambah jika dibutuhkan.

Dalam proses pembuatan beton, air merupakan salah satu bahan yang sangat penting untuk menghasilkan beton yang berkualitas, kuat dan memiliki durabilitas yang baik. Dalam standar beton yang ada, penggunaan air untuk campuran beton adalah air yang layak di konsumsi oleh masyarakat untuk kebutuhan rumah tangga dan umum tanpa kandungan zat yang berbahaya bagi kesehatan. Dengan pertumbuhan penduduk yang terus meningkat maka kebutuhan air untuk kehidupan manusia juga akan terus bertambah. Sejalan dengan hal tersebut ketersedian air layak konsumsi juga akan semakin terbatas atau tidak cukup, sehingga inipun akan berdampak negatif terhadap kebutuhan air tawar untuk 
pembuatan beton. Terbukti di negara kita setiap tahun terdapat beberapa wilayah yang mengalami krisis air.

Sejumlah penelitian terhadap potensi pemanfaatan air laut sebagai air campuran beton telah banyak dilakukan. Sebanyak 68 paper sejak tahun 1974 hingga 2011 yang mengkaji potensi air laut untuk campuran beton diperoleh dari data base Japan Science and Technology Agency (JST) oleh Takahiro Nishida dkk. Kajian tersebut terbagi dalam beberapa aspek seperti aspek kekuatan, korosi dan daya tahan beton. Dalam kurung waktu sepuluh tahun terakhir ini, riset terhadap pemanfaatan air laut sebagai air pencampuran beton masih terus dilakukan. Sebagian besar hasil penelitian menunjukan bahwa air laut memberi dampak positif terhadap kinerja beton [1]-[5].

Namun di sisi lain, beberapa negara yang memiliki standar beton belum merekomendasikan penggunaan air laut sebagai air campuran beton. Hal ini karena mereka masih menilai adanya potensi lebih dini korosi pada tulangan akibat adanya klorida pada senyawa air laut. Oleh karena itu penelitian yang berkelanjutan untuk memahami lebih dalam pengaruh air laut sebagai air pencampuran dan perawatan beton terhadap perilaku beton perlu terus dilakukan.

\section{A. Dasar Teori}

Dalam perencanaan campuran beton, kekuatan beton dinyatakan sebagai kuat tekan beton pada umur 28 hari atau f'c. Kekuatan didefnisikan sebagai kemampuan beton untuk menahan tegangan yang diberikan tanpa mengalami kegagalan atau failure. Kekuatan beton secara umum tergantung pada kekuatan agregat, jenis semen dan kekuatan lekatan antara semen dan agregat. Tegangan tekan beton dapat dinyatakan dengan persamaan 1 berikut :

$$
\sigma_{\text {telan }}=\frac{P}{A}
$$

Keterangan : $\mathrm{P}$ adalah beban tekan yang bekerjapada benda uji silinder $(\mathrm{kg}$, Newton atau $\mathrm{N}, \mathrm{kN})$, dan A adalah luas penampang Silinder $\left(\mathrm{cm}^{2}\right.$ atau $\left.\mathrm{mm}^{2}\right)$

Porositas merupakan faktor utama yang mempengaruhi kekuatan dari beton. Sejumlah faktor yang bisa mempengaruhi porositas beton yaitu rasio airsemen, derajat hidrasi, kandungan udara, bahan tambah, agregat, reaksi antara agregat dengan pasta semen dan komposisi campuran. Porositas adalah ruang kosong atau pori yang ada dalam beton yang tidak terisi oleh pasta semen dan agregat. Pori terbentuk akibat proses hidrasi dan penguapan yang terjadi pada beton. Semakin banyak air yang digunakan dalam proses hidrasi maka potensi untuk terbentuknya pori yang banyak menjadi besar. Pori-pori ini berdiameter 3,2 hingga $3.000 \mathrm{~nm}$ [6]. Dengan bertambahnya umur beton, pori-pori dalam beton berhenti tersambung sebagai fungsi rasio airsemen dan perawatan.

Sejumlah investigasi mencoba menetapkan hubungan antara porositas, kuat tekan dan sifat ketahanan beton. Satu persen peningkatan porositas dalam beton menyebabkan pengurangan kekuatan beton sekitar 5-6\%. Beton memiliki sifat ketahanan yang lebih baik jika memiliki porositas yang lebih rendah. Bersamaan dengan itu akan memberikan kekuatan yang lebih tinggi. Sejumlah model dikembangkan untuk menggambarkan hubungan antara porositas dengan kekuatan beton. Berdasarkan ASTM C 642-97, untuk mencari porositas beton dapat digunakan Persamaan 2 .

$$
n=\frac{C-A}{C-D} \times 100 \%
$$

Keterangan :

$\mathrm{n}=$ porositas benda uji

$\mathrm{C}=$ berat benda uji jenuh air setelah pendidihan $(\mathrm{kg})$

$\mathrm{A}=$ berat kering oven benda uji $(\mathrm{kg})$

$\mathrm{D}=$ berat benda uji dalam air $(\mathrm{kg})$

Sorptiviti sebagai salah satu mekanisme transportasi zat cair atau gas ke dalam beton adalah besaran gaya kapiler yang diberikan oleh pori-pori yang menyebabkan cairan dapat ditarik ke dalam beton. Sorptiviti beton yang kecil memberi indikasi bahwa beton memiliki jumlah pori yang sedikit (permiabilitas rendah). Hal ini akan memberi dampak terhadap peningkatan ketahanan beton terhadap penetrasi klorida atau zat berbahaya masuk ke dalam beton . Beberapa peneliti mengusulkan penggunaan sorptiviti sebagai parameter penting dalam mengukur potensi durabilitas beton.

Untuk kondisi aliran satu dimensi dapat dinyatakan secara matematis hubungan antara jumlah kumulatif penyerapan air persatuan luas permukaan dengan waktu yang terjadi seperti pada persamaan berikut:

$$
\mathrm{I}=\mathrm{S} . \mathrm{t}^{1 / 2}
$$

Keterangan :

$\mathrm{I}=$ Jumlah kumulatif penyerapan air persatuan luas

$\mathrm{S}=$ Sorptiviti

$\mathrm{t}=$ Waktu yang digunakan 


\section{Metode Penelitian}

Penelitian ini dilakukan di laboratorium struktur dan bahan teknik sipil Politeknik Negeri Ujung. Dalam penelitian ini dilakukan kajian eksperimental terhadap sejumlah benda uji berbentuk silinder beton ukuran $15 \mathrm{~cm} \times 30 \mathrm{~cm}$ dan $10 \mathrm{~cm} \times 20 \mathrm{~cm}$. Pengujian kuat tekan beton, porositas dan sorptiviti dilakukan setelah perawatan beton selama 28 hari. Mutu beton rencana adalah f'c $25 \mathrm{Mpa}$ dengan kandungan semen $450 \mathrm{~kg} / \mathrm{m}^{3}$. Perencanaan campuran beton diawali dengan uji karakteristik agregat yang dilakukan dengan mengacu pada ASTM vol.04.02 untuk agregat. Selanjutnya pembuatan benda uji silinder beton mengacu pada standar ASTM C192, perawatan benda uji mengacu standar ASTM C31-00, pengujian kuat tekan beton mengacu pada ASTM C39 - 04, pengujian porositas beton mengacu pada standar ASTM C642-97 dan pengujian sorptiviti mengacu pada standar ASTM C1585-04.

\section{Hasil dan Pembahasan}

\section{A. Hasil Pengujian Karakteristik Agregat}

Dalam perencanaan campuran beton, pengujian karakteristik agregat yang akan digunakan harus dilakukan agar diperoleh hasil campuran beton yang ekonomis dan kualitas yang lebih baik. Oleh karena itu dalam penelitian ini dilakukan uji karakteristik agregat dengan mengacu pada standar ASTM. Hasil uji karakteristik material diperlihatkan pada tabel 1.

\begin{tabular}{|c|c|c|c|c|c|}
\hline No & Uraian & Hasil & $\begin{array}{c}\text { Spesifik } \\
\text { asi }\end{array}$ & Standar & Ket \\
\hline 1. & $\begin{array}{c}\text { Kadar air } \\
\text { bt.pecah }\end{array}$ & $2,06 \%$ & $\begin{array}{c}0,5 \%- \\
2 \%\end{array}$ & $\begin{array}{c}\text { ASTM } \\
\text { C566 }\end{array}$ & Relatif \\
\hline 2. & $\begin{array}{c}\text { Penyerapa } \\
\text { n bt. } \\
\text { pecah }\end{array}$ & $2,99 \%$ & $\begin{array}{c}0,2 \%- \\
2 \%\end{array}$ & $\begin{array}{c}\text { ASTM } \\
\text { C129 }\end{array}$ & Relatif \\
\hline 3. & $\begin{array}{c}\text { Berat } \\
\text { jenis SSD } \\
\text { bt.pecah }\end{array}$ & 2,62 & $\begin{array}{c}1,6- \\
3,2\end{array}$ & $\begin{array}{c}\text { ASTM } \\
\text { C129 }\end{array}$ & $\begin{array}{c}\text { Memen } \\
\text { uhi }\end{array}$ \\
\hline 4. & $\begin{array}{c}\text { Berat } \\
\text { volume } \\
\text { bt.pecah }\end{array}$ & 1,57 & $1,6-1,9$ & $\begin{array}{c}\text { ASTM } \\
\mathrm{kg} / \mathrm{lt}\end{array}$ & $\begin{array}{c}\text { Memen } \\
\text { uhi }\end{array}$ \\
\hline 5 & $\begin{array}{c}\text { Kadar } \\
\text { Lumpur } \\
\text { bt.pecah }\end{array}$ & $0,46 \%$ & $0-1 \%$ & $\begin{array}{c}\text { ASTM } \\
\text { C289 }\end{array}$ & $\begin{array}{c}\text { Memen } \\
\text { uhi }\end{array}$ \\
\hline 6 & Keausan & 33,02 & $15-50$ & ASTM & $\begin{array}{c}\text { Memen } \\
\text { uhi }\end{array}$ \\
\hline 7. & $\begin{array}{c}\text { Kadar air } \\
\text { pasir }\end{array}$ & $4,92 \%$ & $\begin{array}{c}3 \%-5 \\
\%\end{array}$ & $\begin{array}{c}\text { ASTM } \\
\text { C566 }\end{array}$ & $\begin{array}{c}\text { Memen } \\
\text { uhi }\end{array}$ \\
\hline
\end{tabular}

\begin{tabular}{|c|c|c|c|c|c|}
\hline 8. & $\begin{array}{c}\text { Penyerapa } \\
\text { n pasir }\end{array}$ & $3,66 \%$ & $\begin{array}{c}0,2 \%- \\
2 \%\end{array}$ & $\begin{array}{c}\text { ASTM } \\
\text { C129 }\end{array}$ & Relatif \\
\hline 9. & $\begin{array}{c}\text { Berat } \\
\text { jenis SSD } \\
\text { pasir }\end{array}$ & $2,48 \%$ & $\begin{array}{c}1,60- \\
3,20\end{array}$ & $\begin{array}{c}\text { ASTM } \\
\text { C129 }\end{array}$ & $\begin{array}{c}\text { Memen } \\
\text { uhi }\end{array}$ \\
\hline 10. & $\begin{array}{c}\text { Berat } \\
\text { volume } \\
\text { pasir }\end{array}$ & $\begin{array}{c}1,49 \\
\mathrm{~kg} / \mathrm{lt}\end{array}$ & $\begin{array}{c}1,4-1,9 \\
\mathrm{~kg} / \mathrm{lt}\end{array}$ & $\begin{array}{c}\text { ASTM } \\
\mathrm{C} 29\end{array}$ & $\begin{array}{c}\text { Memen } \\
\text { uhi }\end{array}$ \\
\hline 11. & $\begin{array}{c}\text { Kadar } \\
\text { lumpur } \\
\text { pasir }\end{array}$ & $2,26 \%$ & $0-5 \%$ & $\begin{array}{c}\text { ASTM } \\
\mathrm{C} 289\end{array}$ & $\begin{array}{c}\text { Memen } \\
\text { uhi }\end{array}$ \\
\hline 12. & $\begin{array}{c}\text { Modulus } \\
\text { Kehalusan }\end{array}$ & 2,63 & $\begin{array}{c}2,2- \\
3,10\end{array}$ & $\begin{array}{c}\text { ASTM } \\
\text { C136 }\end{array}$ & $\begin{array}{c}\text { Memen } \\
\text { uhi }\end{array}$ \\
\hline
\end{tabular}

\section{B. Hasil perencanaan campuran beton}

Perencanaan campuran beton mengacu pada metode Departement of Environment (DoE). Dari hasil perencanaan campuran dapat disimpulkan komposisi campuran beton dengan mutu f'c $25 \mathrm{Mpa}$ dalam $1 \mathrm{~m}^{3}$ beton diperlihatkan pada tabel 2 dan tabel 3 .

Tabel 2. Kebutuhan bahan campuran beton per $\mathrm{m}^{3}$ secara teoritis (sebelum dikoreksi) Selinder

\begin{tabular}{|c|c|c|l|c|c|c|c|}
\hline Bentuk Benda Uji & Volume & Jumlah \\
$\left(\mathrm{m}^{3}\right)$ & $($ Buah $)$ & $\begin{array}{l}\text { Semen } \\
(\mathrm{kg})\end{array}$ & $\begin{array}{c}\text { Agregat } \\
\text { halus } \\
(\mathrm{kg})\end{array}$ & $\begin{array}{c}\text { Agregat } \\
\text { kasar } \\
(\mathrm{kg})\end{array}$ & $\begin{array}{c}\text { Air } \\
(\mathrm{kg})\end{array}$ & $\begin{array}{c}\text { Berat } \\
\text { total } \\
(\mathrm{kg})\end{array}$ \\
\hline Silinder & 1 & 1 & 450.00 & 577.08 & 1095.60 & 202.33 & 2325 \\
\hline
\end{tabular}

Tabel 3. Kebutuhan bahan campuran beton per $\mathrm{m}^{3}$ di lapangan (setelah dikoreksi) Selinder $(15 \times 30) \mathrm{cm}$

\begin{tabular}{|c|c|c|c|c|c|c|c|}
\hline Bentuk Benda Uji & $\begin{array}{c}\text { Volume } \\
\left(\mathrm{m}^{3}\right)\end{array}$ & $\begin{array}{c}\text { Jumlah } \\
(\mathrm{Buah})\end{array}$ & $\begin{array}{c}\text { Semen } \\
(\mathrm{kg})\end{array}$ & $\begin{array}{c}\text { Agregat } \\
\text { halus } \\
(\mathrm{kg})\end{array}$ & $\begin{array}{c}\text { Agregat } \\
\text { kasar } \\
(\mathrm{kg})\end{array}$ & $\begin{array}{c}\text { Air } \\
(\mathrm{kg})\end{array}$ & $\begin{array}{c}\text { Berat } \\
\text { total } \\
(\mathrm{kg})\end{array}$ \\
\hline Silinder & 1 & $1 \mathrm{~m} 3$ & 450.00 & 577.08 & 1095.60 & 202 & 2325 \\
\hline Silinder & 0.00530 & 5 & 14.31 & 18.35 & 34.83 & 6.43 & 43.99 \\
\hline
\end{tabular}

\section{Hasil Pengujian Kuat Tekan Beton}

Hasil perhitungan kuat tekan beton berdasarkan data uji kuat tekan beton disimpulkan dalam gambar 1 .

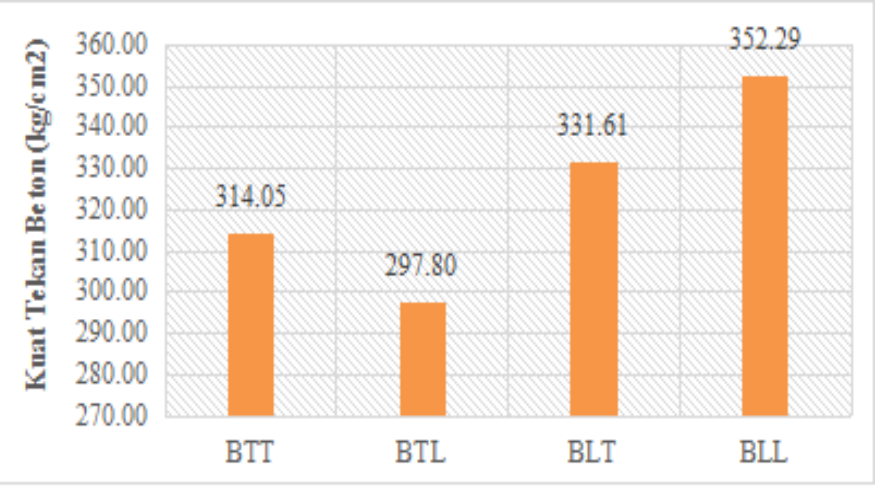

Gambar 1. Histogram kuat tekan beton

Berdasarkan gambar 1 terlihat bahwa kuat tekan beton yang dicampur dengan air laut (BLT dan BLL) 
mengalami peningkatan kuat tekan terhadap kuat tekan beton yang dicampur dengan air tawar (BTT dan BTL). Nilai kuat tekan beton yang dicampur air laut dan dirawat dengan air tawar BLT dan beton yang dirawat dengan air laut BLL adalah masing-masing sebesar $331,61 \mathrm{~kg} / \mathrm{cm}^{2}$ dan $352,29 \mathrm{~kg} / \mathrm{cm}^{2}$. Nilai ini lebih tinggi dari kuat tekan beton yang dicampur dengan air tawar dan dirawat dengan air tawar BTT dan beton yang dirawat dengan air laut BTL dengan kuat tekan beton masing-masing adalah $314,05 \mathrm{~kg} / \mathrm{cm}^{2}$ dan 297,80 $\mathrm{kg} / \mathrm{cm}^{2}$.

\section{Hasil Pengujian Porositas Beton}

Hasil perhitungan porositas beton disimpulakn pada gambar 2.

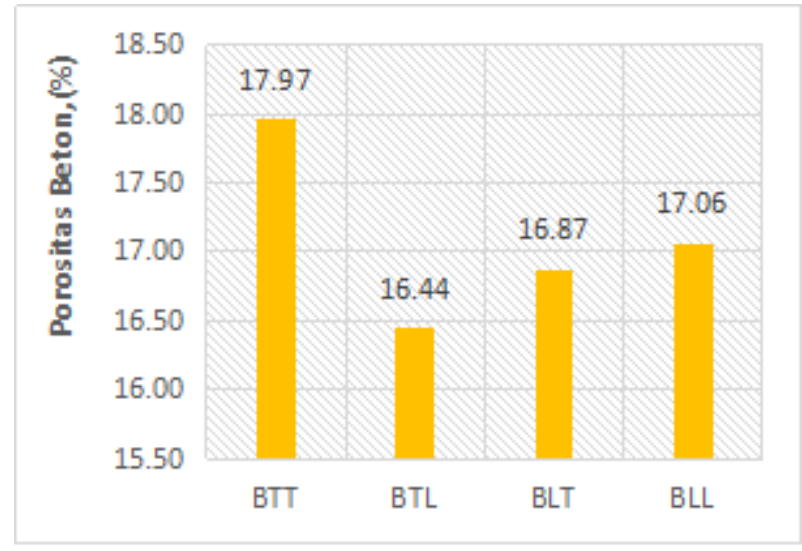

Gambar 2.Histogram Porositas beton

Berdasarkan gambar 2 diatas terlihat adanya penurunan nilai porositas beton yang dicampur dengan air laut dan dirawat dengan air tawar (BLT) dan beton yang dirawat dengan air laut (BLL) terhadap beton yang dicampur dan dirawat dengan air tawar (BTT) sebagai beton pembanding. Nilai porositas beton yang dicampur dengan air laut dan dirawat dengan air tawar ( BLT) dan beton yang dirawat dengan air laut (BLL) masingmasing adalah $16.87 \%$ dan $17.06 \%$. Nilai ini lebih rendah terhadap nilai porositas beton yang dicampur dengan air tawar dan dirawat dengan air tawar (BTT) sebesar $17.97 \%$ sebagai beton pembanding. Beton dengan porositas terendah ditunjukan oleh beton yang dicampur air tawar dan dirawat dengan air laut sebesar $16.44 \%$.

\section{E. Hasil Pengujian Sorptivity Beton}

Hasil perhitungan sorptivity beton disimpulkan dalam gambar 3.

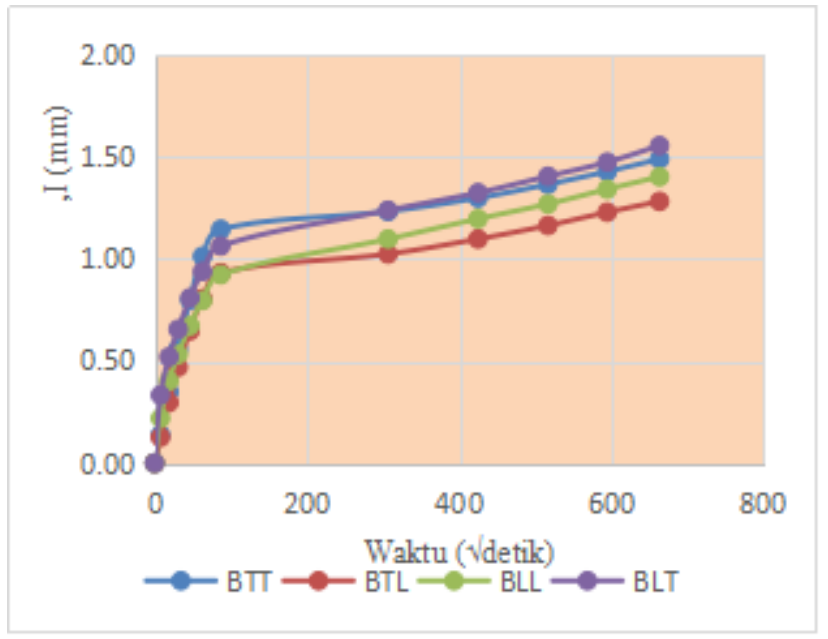

Gambar 3. Sorptiviti Beton

Gambar 3 menunjukkan sifat sorptiviti beton yang lebih baik ditunjukkan oleh beton yang dirawat atau terendam dengan air laut.

\section{Kesimpulan}

\section{A. Kesimpulan}

Berdasarkan hasil analisis dan pembahasan maka dapat diambil kesimpulan sebagai berikut :

1. Kuat tekan beton yang dicampur dengan air laut (BLT dan BLL) mengalami peningkatan kuat tekan terhadap kuat tekan beton yang dicampur dengan air tawar (BTT dan BTL).

2. Porositas beton yang dicampur dengan air laut dan dirawat dengan air tawar (BLT) dan beton yang dirawat dengan air laut (BLL) mengalami penurunan terhadap porositas beton yang dicampur dengan air tawar dan dirawat dengan air tawar (BTT) sebagai beton pembanding.

3. Kuat tekan beton yang dicampur dan dirawat dengan air laut (BLL) diperoleh $352,29 \mathrm{~kg} / \mathrm{cm}^{2}$ dengan porositas sebesar beton $17,06 \%$. Kuat tekan beton yang dicampur air laut dan dirawat dengan air tawar (BLT) diperoleh $331,61 \mathrm{~kg} / \mathrm{cm}^{2}$ dengan porositas beton $16,87 \%$. Kuat tekan beton yang dicampur dengan air tawar dan dirawat dengan air tawar (BTT) sebagai beton pembanding diperoleh 314,05 $\mathrm{kg} / \mathrm{cm}^{2}$ dengan porositas $17,97 \%$. Kuat tekan beton yang dicampur dengan air tawar dan dirawat dengan air laut (BTL) diperoleh 297,80 $\mathrm{kg} / \mathrm{cm}^{2}$ dengan porositas $16,44 \%$. 


\section{B. Saran}

Dari kesimpulan di atas maka dapat disarankan sebagai berikut :

1. Perlu dilakukan penelitian lanjutan dengan membuat beberapa variabel tambahan untuk mendapatkan hasil yang lebih akurat

2. Kajian pengaruh air laut terhadap sifat-sifat beton normal dan beton mutu tinggi yang lain perlu dilakukan.

\section{Ucapan Terima Kasih}

Pada kesempatan ini kami ucapkan terima kasih kepada beberapa pihak yang telah membantu sehingga penelitian ini dapat dilaksanakan yaitu:
a. Direktur Politeknik Negeri Ujung Pandang
b. Ketua jurusan teknik sipil Politeknik Negeri Ujung Pandang
c. Ketua dan staff UPPM politeknik Negeri Ujung Pandang

d. Teman-teman staf Jurusan Teknik Sipil Politeknik Negeri Ujung Pandang serta pihak lain yang tidak sempat disebutkan.

\section{Daftar Pustaka}

[1] Erniati, M. Wihadi Tjaronge, dkk.," Porosity, pore size and compressive strength of self compacting concrete using sea water ".The 5th International Conference of Euro Asia Civil Engineering Forum (EACEF-5), (2015)

[2] Adiwijaya, " A fundamental Study on Seawater-Mixed Concrete Related to Strength, Carbonation And Alkali Silica Reaction “, Kyusu University, 2015

[3] Furuya, D., Otsuki, N., Saito, T., Lee Yun.," A Study On The Effects Of Seawater as Mixing Water on The Hydration Characteristics of Blast-Furnace Slag Cement ", 34thConference on Our World In Concrete \& Structure: 16 - 18 August 2009, Singapore.

[4] Falah M. Wegian, "Effect of seawater for mixing and curing on structural concrete "Department of Civil Engineering, College of Technological Studies (PAAET), 42325 Shuwaikh, 70654 Kuwait (Received 6 August 2010; final version received 1 September 2010

[5] Olutoge, F. Adeyemi, Amusan, G. Modupeola," The Effect of Sea Water on Compressive Strength of Concrete "International Journal of Engineering Science Invention ISSN (Online): 2319 6734, ISSN (Print): 2319 - 6726 www.ijesi.org Volume 3 Issue 7 || July 2014 || PP.23-31

[6] Phileo, R.E, “ Freezing and Thawing Resistance of HighStrength Concrete ", NCHRP Synthesis of Highway Practice 129, Transportation Research Board, (1986) 